\title{
Chemical Quantification of Oxygen by EDXS in the Oxidation of the Ni-Mo-W System
}

\author{
C. Angeles-Chavez, J. A. Toledo-Antonio and M. A. Cortes-Jacome \\ Ingenieria Molecular, Instituto Mexicano del Petroleo, Eje Central Lazaro Cardenas Norte 152, C.P. \\ 07730 México, Distrito Federal, MEXICO
}

$\mathrm{X}$-ray spectroscopy is powerful analysis technique for the new materials design where their chemical identification as well as elemental chemical quantification is fundamental requested information. The X-ray spectrometers are attached in a scanning electron microscopy or a transmission electron microscopy. The electron beam is focused in the sample and excites the atoms in the inner shells. During the deactivation process, the atoms emit characteristic X-rays that are detected by the X-ray spectrometer and then these are used to identify and quantify the chemical composition of the sample. All instruments currently working in the world operate under the same basic principles but not so in the spatial resolution, energy resolution and efficiency of the detector and data treatment. These characteristic have vastly been improved through time and as consequence a great improve in the quality of the results. The most important benefits have reflected been in the chemical quantification results through a better precision and exactitude. These parameters are very characteristics for each instrument type and model [1.2]. Then, in order to obtain reliable information about a phenomenon as function of the chemical composition, the operation conditions of the instrument will must be established.

On other hand, in catalysis, the chemical composition data are very important in the formulation of a catalyst and the energy dispersive X-ray spectroscopy is being the fundamental technique to provide this information type, because gives representative results of a catalytic formulation with a small amount of sample and in relatively few minutes. Taking advantage of these capabilities in our spectrometer, an EDAX attached to an environmental scanning electron microscope Philips XL30, we studied the changes in the chemical composition of the catalytic precursor of Ni-Mo-W. Samples with different content of Ni, Mo and W were prepared by conventional chemical methods. The samples obtained were very prone to environmental oxidation therefore a monitoring of the concentration of the oxygen through time was carried out in the sample with the better atomic relation between metals

Before carrying out the study of composition was determined the exactitude and precision of the instrument using a NIST-SRM 1276a-Cupro-Nickel (CDA 715). So, the X-ray spectrometer used generates results with a precision of $\pm 0.1 \mathrm{wt} \%$ for all concentrations and not so for the exactitude. At concentration below $1 \mathrm{wt} \%$, the exactitude was $\pm 0.2 \mathrm{wt} \%$ and this was decreasing as the concentration was increasing. Around $30 \mathrm{wt} \%$, the exactitude was $\pm 0.9 \mathrm{wt} \%$ and around $65 \mathrm{wt} \% \pm 1.0 \mathrm{wt} \%$. Based in these data was proceeded to analysis the sample as synthesized. Typical EDX spectrum obtained is illustrated in Figure 1. Chemical identification was realized by means of a detailed analysis of the deconvolution of each Gaussian peak. Therefore, $\mathrm{Si}$ and $\mathrm{P}$ in addition to oxygen and the metallic elements were presents in the sample. The elemental chemical composition of the sample with the better metallic atomic ratio is illustrated in table 1 . The metallic atomic ratio obtained was $\mathrm{Ni} /(\mathrm{W}+\mathrm{Mo})=1.0093$ which was very near to the calculated for the preparation. A subsequently analysis of the same sample changed the oxygen concentration. An oxygen amount major was detected. The value was bigger than instrumental error, $>0.9 \mathrm{wt} \%$. Therefore, the result could indicate that the sample could have absorbed 
water or oxygen molecules of the environment or could be a measurement error. To give answer to this uncertainty, more analysis through time was performed. An increase in the oxygen concentration and a decrease in the $\mathrm{Ni}$ concentration were detected in the results. After thirteen months of monitoring, the final composition obtained is reported in table 2 . An increase of $4.56 \mathrm{wt} \% \mathrm{O}$ and a decrease of $2.4 \mathrm{wt} \%$ $\mathrm{Ni}, 1.24 \mathrm{wt} \% \mathrm{Mo}, 0.77 \mathrm{wt} \% \mathrm{~W}$ and $0.15 \mathrm{wt} \% \mathrm{Si}$, were observed. The metallic atomic ratio also decreased, $\mathrm{Ni} /(\mathrm{W}+\mathrm{Mo})=.9492$. As can be seen, at this moment of the investigation, the sample is sensitive to the environmental oxygen. Their presence affects more the $\mathrm{Ni}$ concentration and consequently decreases the atomic ratio.

\section{References:}

[1] J. J. Friel, "X-ray and image analysis in electron microscopy", ed. PGT (Princeton Gamma-Tech Publisher, USA) p.39, 2004.

[2] C. Angeles-Chavez, M.A. Cortes-Jacome, J.A. Toledo-Antonio "Chemical quantification of Mo-S, W-Si and Ti-V by energy dispersive X-ray spectroscopy, X-ray spectroscopy, Chapter 7, Edited by Shatendra K. Sharma, Published by Intech, First published January, 2012, Printed in Croatia.

[3] The authors acknowledge financial support to IMP through project D.00447.

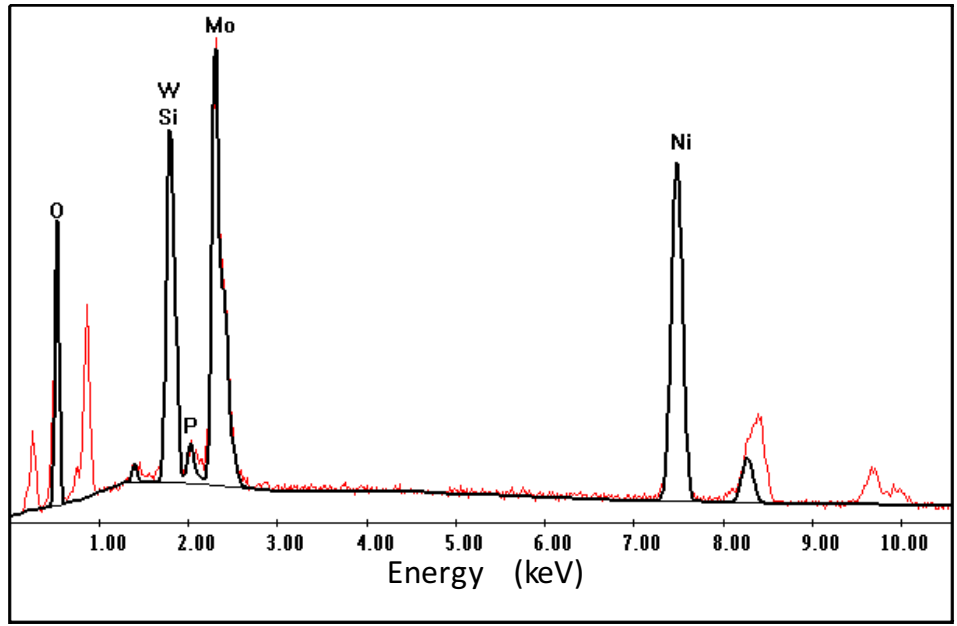

Figure 1. Typical experimental EDX spectrum obtained from the samples, red line. The black line corresponds to the calculated data after deconvolution process.

\begin{tabular}{|c|c|c|}
\hline \multicolumn{3}{|c|}{ Table 1. As synthesized } \\
\hline \multicolumn{3}{|c|}{ Elemental chemical composition } \\
\hline Element & Wt $\%$ & At \% \\
\hline & & \\
\hline O K & 22.82 & 61.98 \\
\hline SiK & 0.92 & 1.42 \\
\hline W M & 25.84 & 6.11 \\
\hline P K & 0.71 & 1.00 \\
\hline MoL & 25.58 & 11.60 \\
\hline NiK & 24.13 & 17.88 \\
\hline Total & 100 & 100 \\
\hline
\end{tabular}

\begin{tabular}{|c|c|c|}
\hline \multicolumn{3}{|c|}{ Table 2. After thirteen months } \\
\hline \multicolumn{3}{|c|}{ Elemental chemical composition } \\
\hline Element & Wt \% & At $\%$ \\
\hline & & \\
\hline O K & 27.38 & 67.84 \\
\hline SiK & 0.77 & 1.09 \\
\hline W M & 25.07 & 5.41 \\
\hline P K & 0.71 & 0.91 \\
\hline MoL & 24.34 & 10.06 \\
\hline NiK & 21.73 & 14.69 \\
\hline Total & 100 & 100 \\
\hline
\end{tabular}

